\section{BREVES CONSIDERAÇÕES SOBRE MEDIDA SOCIOEDUCATIVA E FORMAÇÃO DE PROFESSORES}

\section{BRIEF CONSIDERATIONS ON SOCIO-EDUCATIONAL MEASURES AND TEACHER TRAINING}

Jalusa Silva de Arruda ${ }^{1, *}$ / Otto Vinicius Agra Figueiredo ${ }^{2}$

\section{Introduzindo o tema: do paradigma da situação irregular à doutrina da proteção integral}

Desde sua especialização, a política voltada para o atendimento de crianças e adolescentes ocupou-se dos processos educacionais e assistenciais. O Código de Mello Mattos (Decreto n. 17.943-A, de 12 de outubro de 1927), primeira legislação a tratar especificamente de crianças e adolescentes em nosso país, reforçou a esfera educacional das ações cabíveis ao menor infrator ou abandonado. Numa lógica assistencial e de controle social, para o Código de Mello Mattos o menor abandonado, entre outras situações, era aquele que se encontrava em estado habitual de vadiagem, mendicidade ou libertinagem; privados habitualmente dos alimentos ou dos cuidados indispensáveis à saúde; excitados para gatunice ou que vivessem em companhia de pai, mãe, tutor ou pessoa que se entregasse à prática de atos contrários à moral e aos bons costumes (PEREIRA, 2008; VERONESE, 1999). Nos idos de 1940, no autoritarismo do Estado Novo, a política nacional para menores carentes, abandonados e infratores tinha orientação correcional repressiva baseado em internatos, reformatórios ou casas de detenção que rapidamente se estenderam por todo país (PEREIRA, 2008). A perspectiva de reeducação era baseada no binômio correção-repressão e desenvolvida em internatos para adolescentes autores de infração penal e em escolas agrícolas e escolas de aprendizagem de trabalhos urbanos (SARAIVA, 2003).

\section{RESUMO}

O artigo aborda, sucintamente, a política de atendimento socioeducativo desde a implantação do Sistema Nacional de Atendimento Socioeducativo (Lei 12.594/12) e a centralidade da educação na ação socioeducativa. Adota como metodologia revisão da literatura e ressalta a diretriz da escolarização como estruturante do sistema socioeducativo. Conclui pela importância da formação inicial e continuada de profissionais da educação básica para atuação no sistema socioeducativo.

Palavras-chave: Sistema socioeducativo. Medidas socioeducativas. Formação de professores. Educação básica.

\section{ABSTRACT}

The article briefly discusses the policy of socio-educational assistance since the implementation of the National System of Social-Educacional Service (Law 12.594/12) and the centrality of education in socio-educational action. It adopts as methodology a review of the literature and emphasizes the directing of schooling as structuring of the socioeducational system. It concludes by the importance of the initial and continuous training of professionals of basic education to work in the socio-educational system.

Keywords: Socio-educational system. Educational measures. Teachers' training. Basic education.

Submetido em: 20 de jun. 2018

Aceito em: 07 de nov. 2018

${ }^{1}$ Departamento de Educação, campus XV, Universidade do Estado da Bahia, Valença, Bahia - Brasil.

${ }^{2}$ Departamento de Educação, Universidade Estadual de Feira de Santana, Feira de Santana, Bahia - Brasil.

*E-mail para correspondência: jsarruda@uneb.br 
Logo após o golpe militar, ainda em 1964 foi instituída a Fundação Nacional de Bem-Estar do Menor, com atuação em todo território nacional e que formulou e implantou a Política Nacional de Bem-Estar do Menor. Nos estados brasileiros a Política Nacional de Bem-Estar do Menor foi desempenhada pelas Fundações Estaduais de Bem-Estar do Menor, conhecidas pela sigla FEBEM. A Fundação Nacional de Bem-Estar do Menor centralizou na União a política de atendimento e se tornou o órgão nacional responsável pelo atendimento a crianças e adolescentes infratores e desvalidos. Era, por fim, a concepção de que o menor era assunto de Estado (VERONESE, 1999).

Em 10 de outubro de 1979 foi instituída a Lei 6.697, conhecida como Código de Menores, que considerou o menor como objeto de tutela do Estado e legitimou a intervenção estatal sobre aqueles em situação irregular (SARAIVA, 2003). O Código de Menores dispunha sobre a assistência, proteção e vigilância dos menores e apresentou muitas similaridades com situações compreendidas para o menor abandonado na vigência do Código de Mello Mattos, neste momento denominado situação irregular. $\mathrm{O}$ Código de Menores não diferenciava situações de abandono ou negligência (pela família, Estado ou sociedade) da prática infracional, bem como não adotava medidas diferentes para esses casos: bastava que os menores se enquadrassem numa das situações definidas como sendo irregular para ensejar, indistintamente, intervenção estatal sobre suas vidas. Viu-se neste período uma ampla institucionalização de crianças e adolescentes que tinham seus direitos violados pela família, pelo Estado e pela sociedade em nome da proteção, ressocialização e educação. O caráter social implícito das medidas adotadas aos menores tanto no Código de Mello Mattos como no Código de Menores era de controle social da infância e juventude pobre e desvalida do país, com forte preocupação com a (re)educação e ressocialização, mas não para a emancipação e liberdade, mas sim para a reprodução da ordem social vigente.

Somente com a promulgação da Constituição da República Federativa do Brasil de 1988 e o advento do Estatuto da Criança e do Adolescente (Lei 8.069, de 13 de julho de 1990) que a visão sobre crianças e adolescentes muda no Brasil. No cenário da redemocratização do país houve grande mobilização dos movimentos sociais para mudanças legislativas e fortalecimento de políticas públicas especializadas. $\mathrm{O}$ segmento infanto-juvenil foi privilegiado e a Assembleia Nacional Constituinte agregou no texto do que viria ser a Constituição Federal a concepção da proteção integral. Ao instituir um novo paradigma, a Constituição de 1988 estabeleceu a doutrina da proteção integral:

Art. 227. É dever da família, da sociedade e do Estado assegurar à criança, ao adolescente e ao jovem, com absoluta prioridade, o direito à vida, à saúde, à alimentação, à educação, ao lazer, à profissionalização, à cultura, à dignidade, ao respeito, à liberdade e à convivência familiar e comunitária, além de colocá-los a salvo de toda forma de negligência, discriminação, exploração, violência, crueldade e opressão ${ }^{3}$.

${ }^{3} \mathrm{~A}$ Emenda Constitucional n ${ }^{\circ}$ 65, de 13 de julho de 2010 incluiu o jovem como destinatário da doutrina da proteção integral.
A doutrina da proteção integral rompeu com os pressupostos da doutrina da situação irregular e apresentou um conjunto de regras e sistemas articulados em rede com o objetivo de garantir todas as necessidades de crianças e adolescentes em primazia absoluta; crianças e adolescentes deixaram de ser menores meros objetos de intervenção judicial e passaram a condição de sujeito de direitos, considerados pessoas em condição peculiar de desenvolvimento e destinatários de prioridade absoluta (PEREIRA, 2008; SARAIVA; 2003; SPOSATO, 2006; VERONESE, 1999). Reconheceu-se, com a doutrina da proteção integral, a cidadania contida na infância e na adolescência.

Especificamente quanto a responsabilização pela autoria de ato infracional (toda conduta descrita como crime ou contravenção penal) a Constituição de 1988 estabeleceu a inimputabilidade penal aos menores de 18 anos de idade, sujeitos a legislação especial, quer seja o Estatuto da Criança e do Adolescente ${ }^{4}$. Com a promulgação do Estatuto da Criança e do Adolescente e o estabelecimento da doutrina da proteção integral ocorreram inúmeras modificações quanto a responsabilização dos penalmente inimputáveis em razão da idade que cometiam ilícitos penais. Dentre as principais mudanças destaca-se o estabelecimento da aplicação de medidas de proteção às crianças autoras de ato infracional e de medidas socioeducativas aos

\footnotetext{
${ }^{4}$ Antes da Constituição Federal, o Código Penal de 1940 (Decreto-Lei no 2.848, de 7 de dezembro de 1940), após a Reforma Penal ocorrida em 1984 (Lei $\mathrm{n}^{\circ} 7.209$, de 11 de julho de 1984) previu no art. 27 a inimputabilidade penal para pessoas menores de 18 anos.
} 
adolescentes, em substituição à institucionalização indiscriminada vigentes no Código de Mello Mattos e do Código de Menores.

O estabelecimento das medidas socioeducativas e o Sistema Nacional de Atendimento Socioeducativo (SINASE)

Estabelecidas no Estatuto da Criança e do Adolescente, as medidas socioeducativas são ações que constituem respostas legais a determinado comportamento individual considerado ato infracional, aplicadas pela autoridade competente. Adolescentes (pessoa entre 12 anos completos e 18 incompletos) são inimputáveis penalmente, mas estão sujeitos a legislação especial devendo ser responsabilizados pelas infrações que virem a praticar sujeitando-se à aplicação de medidas socioeducativas ${ }^{5}$. Crianças (pessoas de zero a 12 anos incompletos) que venham a cometer ato infracional não sofrem quaisquer sanções legais: preservam-se todos os seus direitos, cabendo a aplicação de medidas de proteção ${ }^{6}$.

A natureza jurídica das medidas socioeducativas não encontra consenso na literatura especializada. Há aqueles que sustentam que a medida socioeducativa possui caráter sancionatório e punitivo, mas há quem compreenda a medida socioeducativa tão somente na dimensão educativa. Elucida-se, contudo, que isoladamente ambas as perspectivas não estão

\footnotetext{
${ }^{5} \mathrm{~A}$ medida socioeducativa, contudo, poderá ser aplicada até os 21 anos de idade, segundo o parágrafo único do art. $2^{\circ}$, Estatuto da Criança e do Adolescente, de modo que poderá ser utilizado o termo jovem conjuntamente com adolescente para se referir a execução da medida socioeducativa.

${ }^{6}$ Vide artigos 98 e 101, Estatuto da Criança e do Adolescente.
}

corretas: considerar a medida socioeducativa ausente de caráter sancionatório é equipará-la a medida de proteção, o que não é correto, pois assim se equipara o adolescente a uma criança que comete ato infracional; em contrapartida, ao considerar a medida socioeducativa como meramente sancionatória, reprovativa e preventiva ao cometimento de ato infracional é comparar o adolescente como adulto, o que igualmente não está correto. Por certo, a medida socioeducativa tem natureza híbrida, pois apresenta caráter sancionatório-punitivo quanto à imposição, e pedagógico-educacional quanto à execução (FRASSETO, 2006). Isso quer dizer, noutras palavras, que ao ter uma medida socioeducativa imposta o adolescente está sendo responsabilizado pela autoria de um ato previsto como crime ou contravenção penal, mas o objetivo da execução da medida que lhe será imposta repousa na efetivação da garantia de seus direitos e nas ações educacionais e pedagógicas. Cada uma das medidas socioeducativas, desde sua definição, metodologia e especificidade agregará a combinação do caráter reprovatório e educativo cumulativamente, como faces de uma mesma moeda (FRASSETO, 2006). Segundo o art. 112 e seguintes do Estatuto da Criança e do Adolescente, as medidas socioeducativas são:

1) Advertência: consiste em admoestação verbal, reduzida a termo e assinada (art. 115);

2) Obrigação de reparar o dano: em se tratando de ato infracional com reflexos patrimoniais, a autoridade competente pode determinar, se for o caso, que o adolescente restitua a coisa, promova o ressarcimento do dano, ou, por outra forma, compense o prejuízo da vítima (art. 116);

3) Prestação de serviços à comunidade: que consiste na realização de tarefas gratuitas de interesse geral junto a entidades assistenciais, hospitais, escolas e outros estabelecimentos congêneres, bem como em programas comunitários ou governamentais (art. 117);

4) Liberdade assistida: medida adotada sempre que se afigurar a medida mais adequada para o fim de acompanhar, auxiliar e orientar o adolescente (art. 118);

5) Inserção em regime de semiliberdade: medida restritiva de liberdade, o regime de semiliberdade pode ser determinado desde o início, ou como forma de transição para o meio aberto (art. 120);

6) Internação em estabelecimento educacional: constitui medida privativa da liberdade, sujeita aos princípios de brevidade, excepcionalidade e respeito à condição peculiar de pessoa em desenvolvimento (art. 121);

7) Poderão ainda ter aplicadas cumulativamente quaisquer medidas protetivas previstas no art. 101, dos incisos I a VI.

A medida de advertência é aplicada e executada pelo próprio juiz, durante audiência; a obrigação de reparar o dano - muito pouco aplicada no Brasil e de aproximação com 
práticas restaurativas - cabe ao poder judiciário executar, em diálogo com as vítimas dos atos infracionais. As medidas socioeducativas de prestação de serviços a comunidade e liberdade assistida são de meio aberto (implicam restrições de direitos mas sem privação de liberdade) são caracterizadas como serviço socioassistencial de caráter continuado no Sistema Único da Assistência Social (SUAS) e executadas pelo Centro de Referência Especializado da Assistência Social (CREAS). A execução das medidas restritiva e privativa de liberdade, ou seja, semiliberdade e internação (esta última cumprida integralmente em privação de liberdade) são de responsabilidade dos estados da federação.

Apesar das garantias previstas e da determinação de um procedimento específico que para apuração do ato infracional, o Estatuto da Criança e do Adolescente foi sucinto e apresentou conteúdo consideravelmente genérico sobre a forma de executar as medidas socioeducativas. A ausência de definição de parâmetros e procedimentos contribuiu para certa discricionariedade relativa a execução das medidas socioeducativas, o que acabou por tornar terreno fértil para um cenário de violações dos direitos humanos de adolescentes em cumprimento de medida socioeducativa, especialmente em privação de liberdade (BRANCHER; AGUINSKY, 2006; TEIXEIRA, 2006).

$\mathrm{Na}$ tentativa de conter recorrentes violações dos direitos humanos de adolescentes em cumprimento de medidas socioeducativas e de regulamentar a execução das medidas que surgiu o Sistema Nacional de Atendimento Socioeducativo

(SINASE).
Primeiramente instituído como Resolução n. 119 do Conselho Nacional dos Direitos da Criança e do Adolescente (CONANDA), o SINASE objetivou implantar normas $\mathrm{e}$ procedimentos jurídicos e de atendimento padronizados aos adolescentes autores de ato infracional. O SINASE assumiu como "premissa básica a necessidade de se constituírem parâmetros mais objetivos e procedimentos mais justos que evitem ou limitem a discricionariedade" e reafirmou "a diretriz do Estatuto [da Criança e do Adolescente] sobre a natureza pedagógica da medida socioeducativa" (BRASIL, 2006, p. 13). O SINASE propôs parâmetros mínimos para a gestão pedagógica, estrutura arquitetônica e financeira, além de contemplar o monitoramento e a avaliação das unidades. Trouxe orientações para a interação entre as políticas sociais básicas como saúde, educação (formal e profissionalizante), assistência etc., bem como para observância à doutrina da proteção integral.

Desde a instituição do SINASE pelo Conselho Nacional dos Direitos da Criança e do Adolescente foram elaboradas propostas legislativas para detalhar e complementar o Estatuto da Criança e do Adolescente e, finalmente, em 18 de janeiro de 2012 foi sancionada a Lei 12.594, que instituiu o SINASE, regulamentando a execução das medidas destinadas a adolescente que pratique ato infracional. O SINASE tornou-se, portanto, o conjunto ordenado de princípios, regras e critérios que envolvem a execução de medidas socioeducativas incluindo-se os sistemas estaduais, distrital e municipais, bem como todos os planos, políticas e programas específi- cos de atendimento ao adolescente a quem se tenha atribuído a autoria de ato infracional, coordenado pela União e integrado pelos sistemas estaduais, distrital e municipais respectivos (vide $\operatorname{artigos} 1^{\circ}, \S 1^{\circ}$; art. $2^{\circ}$, SINASE).

Fundado na doutrina da proteção integral, o SINASE instituiu princípios que devem reger a execução de todas as medidas socioeducativas, dentre os quais se destaca para este momento de reflexão o princípio $d a$ individualização, que aponta para que seja considerada a idade e capacidade do adolescente no cumprimento da medida socioeducativa; preceitua, que a medida socioeducativa necessita ser planejada de modo que sejam respeitadas as circunstâncias, peculiaridades e características pessoais do adolescente. Para tanto, o SINASE determina que todo adolescente inserido nos programas de execução de medida socioeducativa em meio aberto, restritiva ou privativa de liberdade tenha um Plano Individual de Atendimento (PIA), instrumento que conterá as metas a serem cumpridas na medida por cada adolescente e que garantirá a equidade e individualização na execução da medida. O Plano Individual de Atendimento deve ser elaborado com a equipe que executa a medida socioeducativa, sua família ou responsáveis e o próprio adolescente; contará com planejamento pormenorizado das atividades e ações que serão realizadas na execução da medida socioeducativa e será adotado como parâmetro para a avaliação periódica da medida. O Plano Individual de Atendimento é um instrumento pedagógico por excelência e as atividades educacionais e profissionalizantes são primordiais em 
sua elaboração, compreendidas como ações elementares no processo socioeducativo. Especificamente sobre o direito a educação, para além do direito a matrícula, todo e qualquer adolescente em cumprimento de medida socioeducativa tem direito ao aprendizado que respeite suas habilidades, aptidões e potencialidades de modo que a medida socioeducativa possa, efetivamente, contribuir para sua formação cidadã e oferecer alternativas quando de sua saída do sistema socioeducativo.

Garantir a política pública educacional e a eficiência do direito fundamental à educação no contexto da execução das medidas socioeducativas, sobretudo na medida socioeducativa de internação (executada integralmente em privação de liberdade, recobra-se) é um grande desafio que se estende para além das salas de aula: passa pela ausência de formação docente, que desconhece as especificidades do atendimento socioeducativo; esbarra em metodologias tradicionais de ensino que não consideram as especificidades do perfil de adolescentes que estão no sistema socioeducativo; e carecem de investimento, investigação e sistematização de experiências exitosas e exemplares. Soma-se a essas questões o perfil de adolescentes e jovens de ambos os sexos que estão nos programas de execução de medida socioeducativa pelo país, que indicam que boa parte deles e delas quando da entrada no sistema socioeducativo estava fora da escola. Ainda, majoritariamente em resultados de pesquisas no tema há a identificação de que existe defasagem escolar e distorção idade/série, especialmente quando se trata de adolescentes na medida socioeducativa de internação, e não raro são encontrados adolescentes precariamente alfabetizados. Esses meninos e meninas são, em sua maioria, negros e pobres (ALMEIDA, 2010; ARRUDA, 2011; BRASIL, 2015; 2018; FACHINETTO, 2008; GOMES, 2016; LIMA, 2014; dentre outros). Desde a identificação deste perfil e com alguns resultados de pesquisas pode-se refletir o tema a partir de distintos caminhos, mas este breve trabalho será dedicado a ratificar a importância da formação inicial e continuada de profissionais da educação básica para atuação no sistema socioeducativo, e a necessidade imperiosa dos currículos de formação contemplarem as temáticas afetas ao tema em questão.

\section{Formação inicial e continuada de professores e medidas socioeducativas}

A educação é direito fundamental de toda criança e adolescente, previsto na Constituição Federal, no Estatuto da Criança e do Adolescente e na normativa internacional relacionada ao tema. $\mathrm{O}$ direito a educação visa o pleno desenvolvimento desses que, reconhecidos como pessoas na condição peculiar de desenvolvimento, devem ser preparados para o exercício da cidadania e qualificação para o trabalho (art. 53, Estatuto da Criança e do Adolescente), respeitada a idade. A garantia dos direitos humanos e dos direitos fundamentais independe da eventual atribuição de autoria pela prática de ato infracional; quer dizer, o adolescente em conflito com a lei mantém todos os direitos e a proteção integral atinentes ao segmento infantojuvenil. A educação é concebida como diretriz no atendimento socioeducativo $\begin{array}{llr}\text { e a execução } & \text { das } & \text { medidas } \\ \text { socioeducativas, } & \text { como } & \text { dito }\end{array}$ anteriormente, tem essencialmente natureza pedagógica.

Deste modo, para além de professores de escolas regulares que poderão ter adolescente em conflito com a lei no corpo discente, as equipes técnicas de programas de execução de medidas socioeducativas devem contar com profissionais da educação que irão atuar como professores nas escolas formais existentes nas Unidades de internação (no caso da medida socioeducativa de internação), na coordenação pedagógica, como educadores de medida nos programas de atendimento, educadores físicos, instrutores de oficinas pedagógicas e profissionalizantes etc. ${ }^{7}$ É vasta a possibilidade de atuação de licenciados e pedagogos nos programas de execução de medidas socioeducativas e imprescindível para o desenvolvimento das ações socioeducativas, tanto nas medidas em meio aberto como na restritiva e privativa de liberdade. Não por outro motivo o Conselho Nacional de Educação (CNE) emitiu a Resolução n. 3, de 13 de maio de 2016, instituindo as Diretrizes nacionais para o atendimento escolar de adolescentes $e$ jovens em cumprimento de medidas socioeducativas que representam um avanço para a elaboração e condução de políticas educacionais voltadas para público tão específico. Até então as orientações de cunho mais especificamente pedagógico estavam circunscritas ao previsto no SINASE e no Plano Nacional de Atendimento

\footnotetext{
${ }^{7}$ Art. 12, SINASE. A composição da equipe técnica do programa de atendimento deverá ser interdisciplinar, compreendendo, no mínimo, profissionais das áreas de saúde, educação e assistência social, de acordo com as normas de referência.
} 
Socioeducativo com diretrizes e metas mais gerais no que se refere à aplicação das medidas socioeducativas como um todo. As diretrizes instituídas pela Resolução n. 3/16 tratam especificamente do trato pedagógico para o atendimento escolar de adolescentes e jovens que cumprem medidas socioeducativas em instituições de atendimento, dentre outras questões educacionais mais amplas como a questão da formação inicial e continuada dos docentes, na qual se faz importante um currículo que contemple conteúdos sobre direitos humanos, bem como a obrigatoriedade de componente curricular obrigatório de Educação em Direitos Humanos e de conteúdos relacionados ao cumprimento de medidas socioeducativas. No capítulo que trata dos profissionais que atuam com adolescentes e jovens em atendimento socioeducativo destacamse os seguintes artigos:

Art. 21. Nos cursos de formação inicial e continuada desses profissionais devem ser incluídos conteúdos sobre direitos humanos, direitos das crianças e dos adolescentes, bem como sobre os processos de escolarização de adolescentes e jovens em atendimento socioeducativo.

Art. 22. A Educação em Direitos Humanos deve ser componente curricular obrigatório nos cursos de formação inicial e continuada destinados a esses profissionais.

Art. 23. Os cursos de formação de professores devem garantir nos currículos, além dos conteúdos específicos da respectiva área de conhecimento ou interdisciplinares, seus fundamentos e metodologias, bem como conteúdos relacionados aos direitos educacionais de

$\begin{array}{llr}\begin{array}{l}\text { adolescentes e } \\ \text { cumprimento }\end{array} & \text { dovens } & \text { em } \\ \text { socioeducativas. } & \text { (Grifos } & \text { dos } \\ \text { autores). } & & \end{array}$

As Diretrizes nacionais para $o$ atendimento escolar de adolescentes e jovens em cumprimento de medidas socioeducativas estão em plena sintonia com o preconizado pela Resolução n. 2 , de $1^{\circ}$ de julho de 2015 do Conselho Nacional de Educação, que define as Diretrizes Curriculares Nacionais para a formação inicial em nível superior e para a formação continuada. Essas diretrizes definem o que se compreende como cursos de formação inicial para os profissionais do magistério que atuarão na Educação Básica que são: a) cursos de graduação de licenciatura; b) cursos de formação pedagógica para graduados não licenciados; e c) cursos de segunda licenciatura. Esses cursos implicam em formação em nível superior, preferencialmente de forma presencial primando por elevado padrão acadêmico, científico e tecnológico e cultural, e ficará a cargo das instituições formadoras definirem em seus projetos institucionais as formas de desenvolvimento da formação inicial dos docentes da Educação Básica. Para a presente reflexão chama-se a atenção para o que está disposto a respeito da estrutura e currículo desses cursos de formação. Nas três formas de cursos consta a seguinte exigência nos currículos:

Os cursos de formação deverão garantir nos currículos conteúdos específicos da respectiva área de conhecimento ou interdisciplinares, seus fundamentos e metodologias, bem como conteúdos relacionados aos fundamentos da educação, formação na área de políticas públicas e gestão da educação, seus fundamentos e metodologias, direitos humanos, diversidades étnico-racial, de gênero, sexual, religiosa, de faixa geracional, Língua Brasileira de Sinais (Libras), educação especial e direitos educacionais de adolescentes e jovens em cumprimento de medidas socioeducativas. (Art. $13, \S 2^{\circ}$; art. $14, \S 2^{\circ}$ e $\operatorname{art} .15, \S 3^{\circ}$, Diretrizes Curriculares Nacionais para a formação inicial em nível superior e para a formação continuada) (Grifo dos autores).

Ambas as diretrizes acima referidas ratificam a importância dos direitos educacionais de adolescentes e jovens em cumprimento de medidas socioeducativas estarem contemplados nos currículos de formação dos profissionais da educação que atuarão na Educação Básica atendendo esses adolescentes e jovens, seja nas instituições formais de ensino ou nas escolas das Unidades de atendimento socioeducativo. A literatura especializada aponta que historicamente a educação pensada para uma parte dos adolescentes e jovens em conflito com a lei tinha como referência as Diretrizes Curriculares Nacionais para a Educação de Jovens e Adultos (Resolução n. 1, de 5 de julho de 2000), sem que, no entanto, estivessem diretamente contemplados. Por esse e por outros motivos a aprovação da Resolução n. 2/2015 foi tão importante para a promoção dos direitos educacionais de adolescentes e jovens na medida socioeducativa, em especial a internação (FRANCO; CARVALHO; PEIXOTO, 2018; ROSA et al, 2017).

Ainda em diálogo com as Diretrizes nacionais para o atendimento escolar de adolescentes $e$ jovens em cumprimento de medidas 
com Ciência

Uma revista multidisciplinar

socioeducativas cabe destacar o Plano Nacional de Atendimento Socioeducativo publicado no ano de 2013, e a Portaria n. 4 da Secretaria de Direitos Humanos, publicada em janeiro de 2015 que instituiu a Escola Nacional de Socioeducação, conhecida como Escola do SINASE.

\section{A Escola do SINASE tem} como principal objetivo garantir a formação continuada para os diferentes profissionais que atuam direta ou indiretamente no Sistema Nacional de Atendimento Socioeducativo. Para tanto, previu a Portaria n. 4/15 que a instituiu que deverá haver núcleos estaduais que contribuirão para consolidação de formações articuladas e minimamente integradas a nível nacional. No Plano Nacional de Atendimento Socioeducativo a referência para a formação voltada para o tema direitos humanos, Direito da Criança e do Adolescente, socioeducação e atendimento socioeducativo foi destacada no marco situacional, que identificou a falta de qualificação para a implementação da política de atendimento socioeducativo e a fragilidade e desarticulação da formação dos profissionais que atuam no sistema socioeducativo. Especificamente no eixo Gestão do SINASE, o Plano Nacional de Atendimento Socioeducativo ocupouse da importância do investimento na formação dos profissionais que principal e estrategicamente deve ser oferecida pelas Escolas do SINASE. Deste modo, a qualificação profissional e a formação continuada dos profissionais que atuam no sistema socioeducativo, seja em qualquer nível, são consideradas como fundamentais para plena garantia de direitos de adolescentes que estejam cumprindo medidas socioeducativas.
Outro aspecto a se levar em conta para melhor pensar a garantia do acesso de adolescentes e jovens ao direito à educação formal e a necessária formação docente é a complexidade de circunstâncias que caracterizam o contexto educacional desse público. Como ventilado anteriormente, dados nacionais, estaduais e estudos empíricos apontam características comuns como: adolescentes e jovens majoritariamente da raça negra (pretos e pardos), de faixa etária entre 16 e 18 anos, de famílias desfavorecidas economicamente, oriundos de bairros periféricos, no qual a maioria não completou o ensino fundamental e se encontrava afastada da escola quando da aplicação da medida socioeducativa (FRANCO; CARVALHO; PEIXOTO, 2018). Com isso é possível afirmar que para muitos deles a escola já não representava algo significativo em suas vidas. Além dos marcadores sociais de exclusão como raça e classe, por vezes sobre esses adolescentes e jovens recai o estigma de estarem no sistema socioeducativo ou dele serem egressos (GOFFMANN, 1988). Como efeito deletério do processo de criminalização, esses adolescentes e jovens não raro são rotulados como irrecuperáveis e não aceitos pelo corpo docente, tornando inevitável a evasão escolar.

Esse conjunto de fatores corrobora a necessidade de perceber adolescentes e jovens em conflito com a lei de forma específica; igualmente, é necessário também maior atenção para a formação dos profissionais que atuarão no sistema socioeducativo.

\section{Comentários finais}

Apesar das diretrizes nacionais mencionadas acima apontarem para a formação inicial dos profissionais, no que se refere especificamente à formação dos professores se verifica ausência de formação sólida desses conteúdos e elementos para desenvolvimento de habilidades. Os currículos dos cursos de formação de professores não têm garantido componentes curriculares obrigatórios que deem conta de temas afetos ao sistema socioeducativo, pois, quando muito, estão ofertados em disciplinas optativas. Profissionais da educação têm chegado às unidades de atendimento socioeducativo e/ou às instituições públicas de ensino sem formação específica, preparo adequado ou com conhecimentos superficiais a respeito dos temas relacionados ao Direito da Criança e do Adolescente, Justiça Juvenil e atendimento socioeducativo, mesmo sendo profissionais da educação integrantes das equipes básicas que executam medidas socioeducativas tanto em meio aberto (prestação de serviços a comunidade e liberdade assistida) como restritiva ou privativa de liberdade (semi-liberdade e internação). Nesta breve reflexão ficam os desafios para a formação docente e para efetiva garantia do direito a educação para adolescentes e jovens em conflito com a lei.

A educação na medida socioeducativa, especialmente na privação de liberdade, tem como desafio transpor as noções de controle, disciplina e segurança para efetivamente promover aprendizados que contribuam para uma socioeducação emancipadora. Formar profissionais para esta tarefa é uma atribuição que está posta a todas as categorias que atuam no sistema 
socioeducativo, especialmente para cursos de formação de professores da educação básica, dada a centralidade da escolarização para a eficácia da política pública de execução de medida socioeducativa.

\section{Referências}

ALMEIDA, Bruna Gisi Martins de. A experiência da interação entre adolescentes: práticas punitivas e rotinas institucionais. Dissertação (Mestrado em Sociologia) Universidade de São Paulo, 2010.

ARRUDA, Jalusa Silva de. "Para ver as meninas": um estudo sobre as adolescentes em cumprimento de medida socioeducativa de internação na Case/Salvador. Dissertação (Mestrado em Estudos Interdisciplinares sobre Mulheres, Gênero e Feminismo) - Faculdade de Filosofia e Ciências Humanas, Universidade Federal da Bahia, 2011.

BRANCHER, Leoberdo; AGUINSKY, Beatriz. Juventude, crime e justiça: uma promessa impagável? In: ILANUD, ABMP, SEDH, UNFPA (Org.). Justiça, adolescente e ato infracional: socioeducação e responsabilização. São Paulo: Ilanud, 2006, p. 469-493.

\section{BRASIL. Código de Mello Mattos.}

Decreto n. 17.943-A, de 12 de outubro de 1927. Disponível em: < http://www.planalto.gov.br/ccivil_03/d ecreto/1910-1929/d17943a.htm>

Acesso em: 20 mai. 2018.

BRASIL. Código de Menores. Lei n. 6.697, de 10 de outubro de 1979.

Disponível em: < http://www.planalto.gov.br/ccivil_03/1
eis/1970-1979/L6697.htm> Acesso em: 20 mai. 2018.

BRASIL. Constituição da República Federativa do Brasil de 1988.

Disponível em:

<http://www.planalto.gov.br/ccivil_03/ constituicao/constituicaocompilado.ht m> Acesso em: 20 mai. 2018.

BRASIL. Estatuto da Criança e do Adolescente. Lei n. 8.069, de 13 de julho de 1990. Disponível em: <http://www.planalto.gov.br/ccivil/LE IS/L8069.htm> Acesso: 20 mai. 2018.

\section{BRASIL. Sistema Nacional de} Atendimento Socioeducativo. Lei 12.594, de 18 de janeiro de 2012. Disponível em: < http://www.planalto.gov.br/ccivil_03/_ ato2011-2014/2012/lei/112594.htm>

Acesso em: 20 mai. 2018

BRASIL. Secretaria de Direitos Humanos, Presidência da República. Plano Nacional de Atendimento Socioeducativo. Diretrizes e eixos operativos para o SINASE. Brasília, 2013.

BRASIL. Ministério da Educação. Conselho Nacional de Educação. Diretrizes curriculares nacionais para a formação inicial e continuada em nivel superior de profissionais do magistério para a educação básica. Resolução n. 2, de $1^{\circ}$ de julho de 2015. Disponível em:

$<$ http://portal.mec.gov.br/docman/agos to-2017-pdf/70431-res-cne-cp-00203072015-pdf/file> Acesso em: 20 mai. 2018.

BRASIL. Ministério da Educação. Conselho Nacional de Educação. Diretrizes nacionais para o atendimento escolar de adolescentes $e$ jovens em cumprimento de medidas socioeducativas. Resolução n. 3, de 13 de maio de 2016. Disponível em: $<$ http://portal.mec.gov.br/par/455governo-1745665505/ogaosvinculados-627285149/34011resolucoes-da-camara-de-educacaobasica-ceb-2016> Acesso em: 20 mai. 2018.

BRASIL. Ministério da Educação. Conselho Nacional de Educação. Diretrizes Curriculares Nacionais para a Educação de Jovens e Adultos. Resolução n. 1, 5 de julho de 2000. Disponível em:

<http://portal.mec.gov.br/cne/arquivos/ pdf/CEB012000.pdf> Acesso em: 20 mai. 2018.

BRASIL. Conselho Nacional dos Direitos da Criança e do Adolescente. Sistema Nacional de Atendimento Socioeducativo. Resolução n. 119, de 11 de dezembro de 2006. Disponível em: <

http://www.sdh.gov.br/assuntos/crianc as-e-adolescentes/pdf/plano-nacionalde-atendimento-socioeducativodiretrizes-e-eixos-operativos-para-osinase> Acesso em: 20 mai. 2018.

BRASIL. Secretaria Geral da Presidência da República e Secretaria Nacional de Juventude. Mapa do encarceramento: os jovens do Brasil. Brasília: Presidência da República, 2015. (Série Juventude Viva).

BRASIL. Secretaria Nacional dos Direitos da Criança e do Adolescente. Levantamento Nacional do Sistema Nacional de Atendimento Socioeducativo de 2016. Brasília: Ministério dos Direitos Humanos, 2018. 
FACHINETTO, Rochele Fellini. A

"Casa de Bonecas": um estudo de caso sobre a unidade de atendimento sócio-educativo feminino do RS.

Dissertação (Mestrado em Sociologia) - Instituto de Filosofia e Ciências Humanas, Universidade Federal do Rio Grande do Sul, 2008.

FRANCO, Cássio S.; CARVALHO, Luiz Ramon T.; PEIXOTO, Roberto

B. Educação e sistema socioeducativo: desafios e possibilidades. In:

FRANCO, Cássio S.; FREITAS, Raquel C.; CARVALHO, Luiz Ramon T. (Orgs.). Liberta. Fortaleza: Gráfica LRC, 2018, p. 38-50.

FRASSETO, Américo. Execução da medida socioeducativa de internação: primeiras linhas de uma crítica garantista. In: ILANUD, ABMP, SEDH, UNFPA (Org.). Justiça, adolescente e ato infracional: socioeducação e responsabilização.

São Paulo: Ilanud, 2006, p. 303-342.

GOFFMAN, Erving. Estigma: notas sobre a manipulação da identidade deteriorada. 4. ed. Rio de Janeiro: LTC, 1988.

GOMES, Daiane Daine de Oliveira. Da privação de direitos à privação de liberdade: tecendo trajetórias de adolescentes negras em cumprimento de medida socioeducativa de internação. Dissertação (Mestrado em Serviço Social, Trabalho e Questão Social) - Universidade Estadual do Ceará, 2016.

LIMA, Juliana Vinuto. Entre o "recuperável" e o "estruturado": classificações dos funcionários de medida socioeducativa de internação acerca do adolescente em conflito com a lei. Dissertação (Programa de PósGraduação em Sociologia da Universidade de São Paulo) Universidade de São Paulo, São Paulo, 2014.

PEREIRA, Tânia da Silva. Direito da Criança e do Adolescente: uma proposta interdisciplinar. 2. ed. Rio de Janeiro: Renovar, 2008.

ROSA, Camila S. et al. Escolarização e socioeducação: conversas sobre marcadores sociais e trabalho docente em espaços de privação de liberdade. In: MENDES, Cláudia Lúcia; JULIÃO, Elionaldo Fernandes; VERGÍlIO, Soraya. (Orgs.). Educação, socioeducação e escolarização. Rio de Janeiro: DEGASE, 2017, p. 39-60.

SPOSATO, Karyna Batista. Princípios e garantias para um direito penal juvenil mínimo. In: ILANUD, ABMP, SEDH, UNFPA (Org.). Justiça, adolescente e ato infracional: socioeducação e responsabilização. São Paulo: Ilanud, 2006, p. 247-275.

TEIXEIRA, Maria de Lourdes T. Evitar o desperdício de vidas. In: ILANUD, ABMP, SEDH, UNFPA (Org.). Justiça, adolescente e ato infracional: socioeducação e responsabilização. São Paulo: Ilanud, 2006, p. 427-447.

VERONESE, Josiane Rose Petry. Os direitos da criança e do adolescente. São Paulo: LTr, 1999. 